extraordinarily low plasma ANP concentration. In general, the plasma ANP concentration shows a graded rise in patients with congestive heart failure because atrial distention is a key trigger that stimulates ANP secretion. ${ }^{2}$ This patient underwent closed and open mitral commissurotomy more than 30 years ago, at which time the appendages must have been removed or ligated. We previously reported that the secretory function of ANP was impaired after resection of atrial appendages in experimental heart failure models. ${ }^{3}$ In addition, sustained mitral stenosis and tricuspid regurgitation induced excessive extension of the atria, which may have further diminished the granules producing ANP. Thus it is considered that the patient had a lack of ANP secretion despite congestive heart failure.

Infusion of alpha-ANP was notably effective in this patient in terms of diuresis and in reducing preload level. Saito and associates ${ }^{l}$ first reported the beneficial effect of ANP administration in patients with congestive heart failure. We also reported the hemodynamic effects of ANP infusion after cardiac operation as cardiac output increased and pulmonary arterial pressure decreased. ${ }^{4}$ We recently performed a trial of continuous infusion of ANP for more than 24 hours in more than 10 patients after cardiac operation irrespective of the plasma ANP concentration. In selected patients, ANP infusion markedly increased urine volume whereas in these patients the diuretic effect of furosemide was minimal (unpublished data). Continuous infusion of alpha-ANP should be tried in patients after cardiac operations when oliguria develops.

\section{REFERENCES}

1. Saito Y, Nakao K, Nishimura K, et al. Clinical application of atrial natriuretic polypeptide in patients with congestive heart failure: beneficial effects on left ventricular function. Circulation 1987;76:115-24.

2. Bates ER, Shenker Y, Grekin RJ. The relationship between plasma levels of immunoreactive atrial natriuretic hormone and hemodynamic function in man. Circulation 1986;73:115561.

3. Nishimura K, Saito Y, Hidaka T, et al. Does atrial appendectomy aggravate secretory function of atrial natriuretic polypeptide? J Thorac Cardiovasc Surg 1991;101:502-8.

4. Nishimura K, Fujiwara Y, Okabayashi H, et al. Effects of administration of atrial natriuretic polypeptide in patients after cardiac surgery. J Jpn Cardiovasc Surg 1988;17:649-51.

\title{
PYODERMA GANGRENOSUM AND MYELOFIBROSIS AFTER CORONARY ARTERY BYPASS GRAFTING
}

Louis E. Samuels, MD, ${ }^{a}$ Marla S. Kaufman, BA, ${ }^{a}$ William G. Kussmaul, MD, ${ }^{b}$ and Stanley K. Brockman, MD, ${ }^{a}$ Philadelphia, $\mathrm{Pa}$.

A 66-year-old white man was admitted to the Allegheny University Hospitals, Hahnemann Division, Philadelphia, in April 1996 with unstable angina and shortness of breath. The medical history was significant for coronary artery disease, chronic renal failure, and hypertension. On admission to the hospital, the white blood cell count was 8100 per microliter, hemoglobin and hematocrit levels were $8.5 \mathrm{gm} / \mathrm{dl}$ and $25.1 \%$, and platelet count was 230 K/UL. Cardiac catheterization 2 days after hospital admission showed severe triple-vessel coronary artery dis-

From the Department of Cardiothoracic Surgery and the Department of Medicine, Division of Cardiology, ${ }^{b}$ Allegheny University Hospitals, Hahnemann Division, Philadelphia, Pa.

Received for publication August 26, 1996; accepted for publication Sept. 24, 1996.

Address for reprints: Louis E. Samuels, MD, Allegheny University Hospitals, Hahnemann Division, Broad and Vine Sts., MS 111, Philadelphia, PA 19102-1192.

J Thorac Cardiovasc Surg 1997;113:795-7

Copyright (C) 1997 by Mosby-Year Book, Inc.

$0022-5223 / 97 \$ 5.00+0 \quad \mathbf{1 2 / 5 4 / 7 8 1 7 7}$ ease. Seven days after hospital admission, the patient underwent coronary artery bypass grafting. The immediate postoperative course was uneventful.

On postoperative day (POD) 3 , fever $\left(101.7^{\circ} \mathrm{F}\right)$ and sternal tenderness with serous drainage developed. The white blood cell count was $15 \mathrm{~K} / \mathrm{UL}$. Empiric broad-spectrum antibiotic therapy was started. On POD 5, sternal wound debridement was done. No signs of gross infection were observed. Instead, there was extensive sternal and subcutaneous tissue necrosis. The operative Gram stain test showed negative results for organisms and there was no growth on culture. Skin and subcutaneous tissue necrosis progressed. On POD 6, an abrupt drop in the white blood cell and platelet counts occurred (Figs. 1 and 2). Fever and pancytopenia persisted over the next couple of days.

On POD 13, further sternal wound debridement was done. Similar findings of necrotic uninfected tissue were observed. On POD 19, histopathologic examination of the skin specimens was diagnostic of pyoderma gangrenosum. Steroid therapy (hydrocortisone $100 \mathrm{mg}$ intravenously every 8 hours) was instituted. On POD 28 , the patient underwent a bone marrow biopsy. Myelofibrosis was found. Therapy with bone marrow 


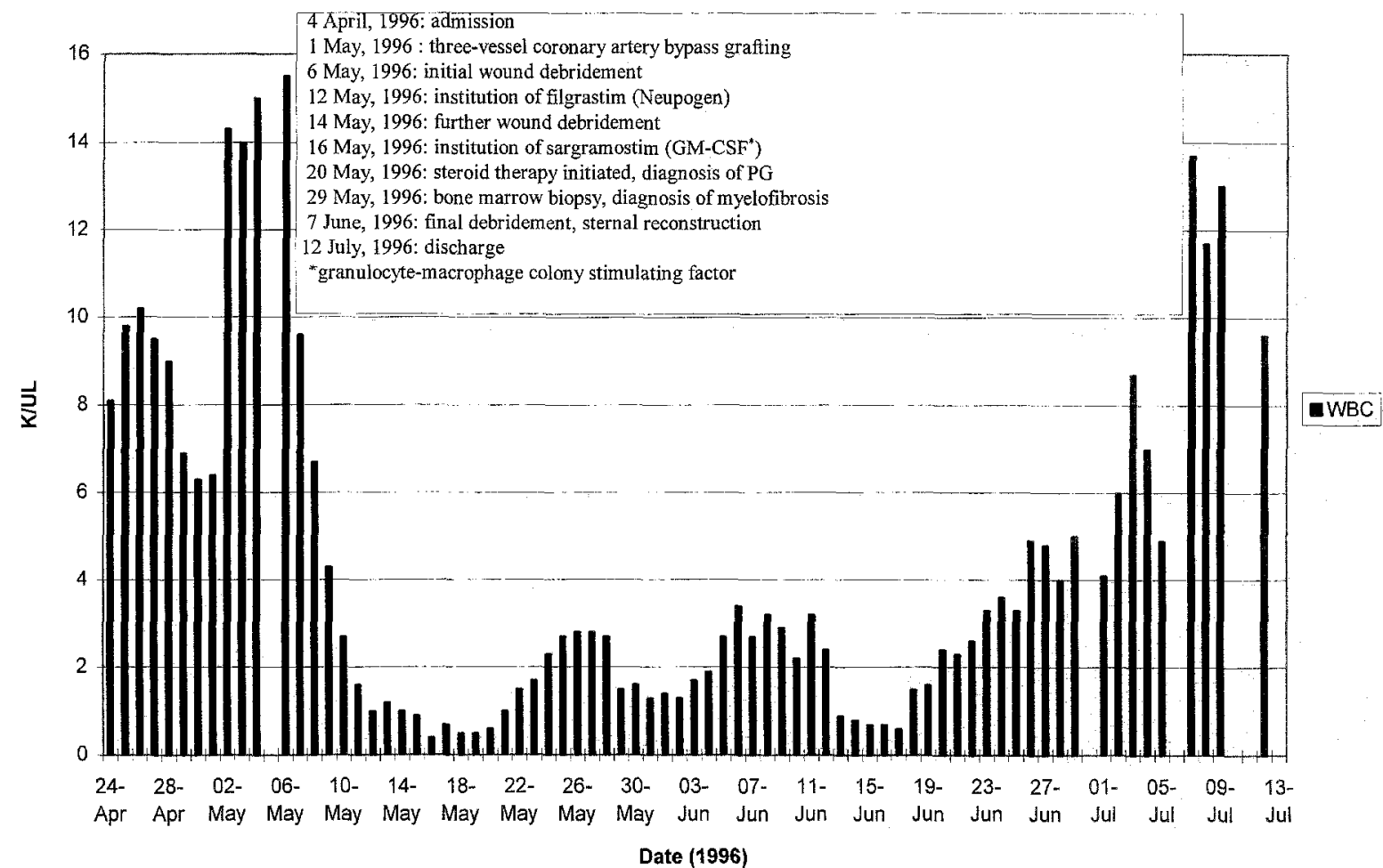

Fig. 1. White blood cell count (WBC). GM-CSF, Granulocyte-macrophage colony stimulating factor; $P G$, pyoderma gangrenosum.

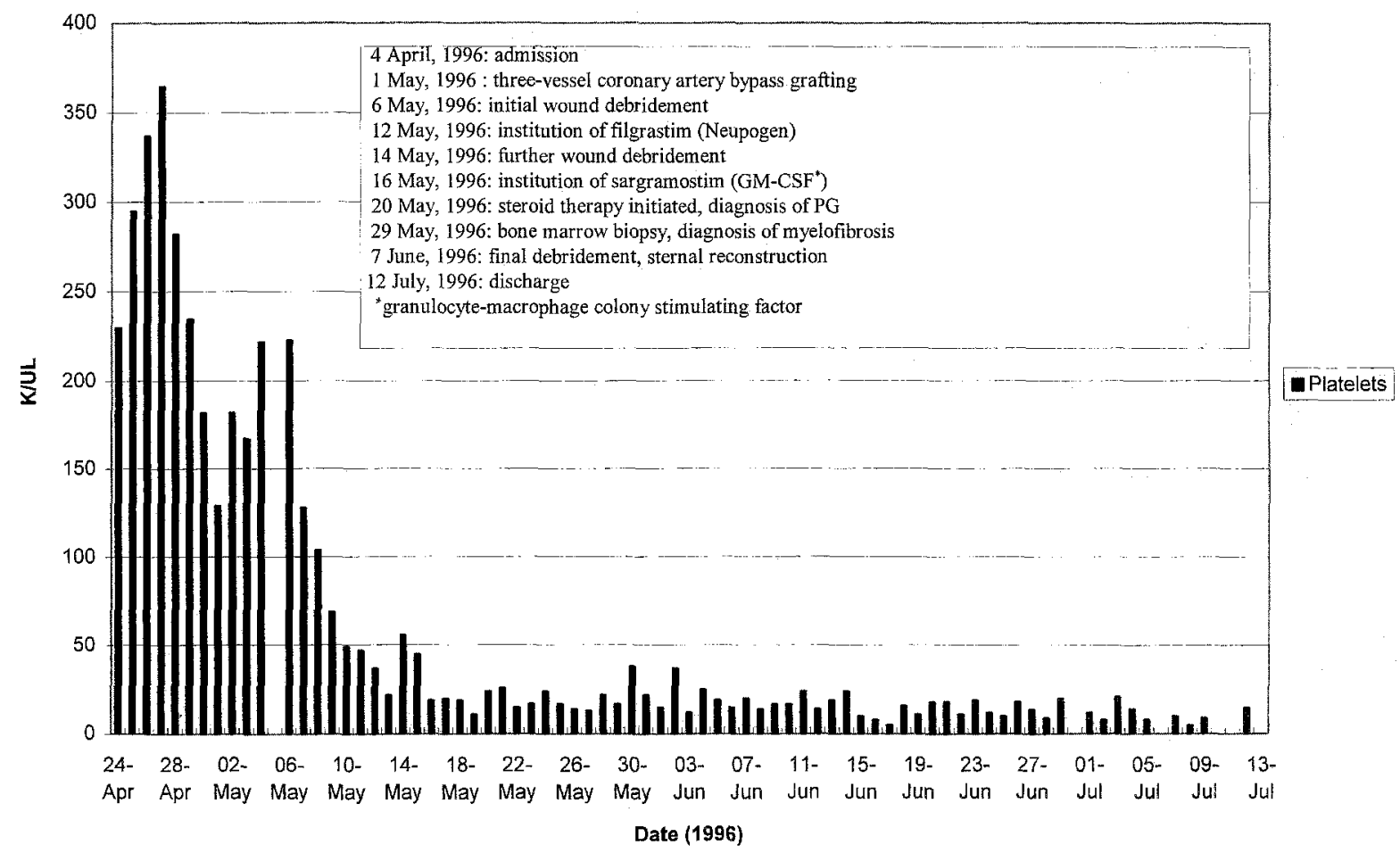

Fig. 2. Platelet count. $G M-C S F$, Granulocyte-macrophage colony stimulating factor; $P G$, pyoderma gangrenosum. 
stimulants was started (filgrastim, $480 \mu \mathrm{g}$ intravenously, and sargramostim, $500 \mu \mathrm{g}$ intravenous piggyback every 12 hours). On POD 37, further debridement and reconstruction of the sternum with omental transfer and split-thickness skin grafting were done.

The remainder of the hospital course was marked by extensive surgical wound care, steroid therapy, intermittent dialysis, chemical bone marrow stimulation, nutritional support, and physical rehabilitation. The patient was transferred to a rehabilitation center on POD 72. At hospital discharge, the white blood cell count was 9.6 $\mathrm{K} / \mathrm{UL}$, hemoglobin and hematocrit values were $7.0 \mathrm{gm} / \mathrm{dl}$ and $21.6 \%$, and platelet count was $15 \mathrm{~K} / \mathrm{UL}$.

Discussion. Pyoderma gangrenosum is a rare disorder and only two case reports document the disease after coronary artery bypass grafting procedures. ${ }^{1,2}$ The cause of pyoderma gangrenosum is unknown. It is, however, immunologic in nature. ${ }^{3}$ Characteristically, the lesions are found after an injury to the skin. ${ }^{2}$ There are no organisms found on Gram stain tests and there is no growth on culture. Typically, there are ulcerations marked by well-defined borders with a blue outline indicating necrosis of the subcutaneous tissue. Although the diagnosis of pyoderma gangrenosum is clinical, there are characteristic histopathologic features: acute and chronic inflammatory changes, endothelial proliferation, loss of the epidermis at the ulcerated sites, and epidermal hyperplasia at the borders.

In our case and in another previously described, ${ }^{4}$ pyoderma gangrenosum was linked to myeloproliferative disease. In the report of Romano and Safai, ${ }^{4}$ the patient was known to have chronic myelocytic leukemia. In that case, the skin lesions responded to a course of oral prednisone beginning with $80 \mathrm{mg}$ per day. ${ }^{4}$ In our case, the disease was discovered during the evaluation of pancytopenia. This delay in diagnosis resulted in further skin and subcutaneous necrosis that necessitated extensive debridement. Once the diagnosis was made, steroid therapy arrested the necrotic process and reversed the cutaneous pathologic changes. In a similar case, cyclosporine A (5 $\mathrm{mg} / \mathrm{kg}$ ) was successfully used to avoid the wound-healing problems associated with steroid use. ${ }^{2}$ In our case, the use of cyclosporine was not an option because of the chronic renal failure and pancytopenia.

The challenging component of our case was the prevention of sepsis in the setting of pancytopenia with extensive open surgical wounds. Broad-spectrum antibiotic coverage, strict isolation, frequent surveillance cultures, and pharmacologic stimulation of the bone marrow were necessary. Despite these steps, various local infections occurred, including dialysis access-related infection and upper respiratory tract infection. Fortunately, systemic involvement was avoided.

In conclusion, concurrent pyoderma gangrenosum and myeloproliferative disease represents a unique and challenging clinical problem. Early recognition of the skin manifestations of pyoderma gangrenosum is necessary so that steroid therapy can be instituted, thereby avoiding radical debridement of wounds. The therapy for the associated pancytopenia requires support of the bone marrow with chemical stimulants. Prophylactic broad-spectrum antibiotic coverage is necessary to prevent sepsis.

\section{REFERENCES}

1. Rand RP, Olerud JE, Verrier ED. Pyoderma gangrenosum after coronary artery bypass grafting. Ann Thorac Surg 1993; 55:1016-8.

2. Koss-Harnes D, Ovrum E, Langeland T. Pyoderma gangrenosum as a complication of coronary artery bypass grafting. Eur J Cardiothorac Surg 1995;9:163-5.

3. Delescluse J, de Bast CL, Achten G. Pyoderma gangrenosum with altered cellular immunity and dermonecrotic factor. $\mathrm{Br} \mathbf{J}$ Dermatol 1972;82:529-32.

4. Romano J, Safai B. Pyoderma gangrenosum and myeloproliferative disorders. Arch Intern Med 1979;139:932-4.

\title{
EFFECTS OF POSTERIOR PERICARDIOTOMY ON THE INCIDENCE OF ATRIAL FIBRILLATION AND CHEST DRAINAGE AFTER CORONARY REVASCULARIZATION: A PROSPECTIVE RANDOMIZED TRIAL
}

\author{
George Asimakopoulos, MD, Renato Della Santa, MD, and David P. Taggart, MD(Hons), FRCS, \\ Oxford, United Kingdom
}

From the Department of Cardiothoracic Surgery, Oxford Heart Center, The John Radcliffe Hospita1, Oxford, United Kingdom.

Received for publication June 25, 1996; accepted for publication Sept. 11, 1996.

Address for reprints: D. P. Taggart, MD (Hons), FRCS, Consultant Cardiothoracic Surgeon, The John Radcliffe Hospital, Oxford OX3 9DU, United Kingdom.

J Thorac Cardiovasc Surg 1997;113:797-9

Copyright (C) 1997 by Mosby-Year Book, Inc.

$0022-5223 / 97 \$ 5.00+0 \quad \mathbf{1 2 / 5 4 / 7 7 8 6 3}$
Supraventricular tachyarrhythmia (SVT), mainly in the form of atrial fibrillation (AF), occurs in up to $40 \%$ of patients undergoing coronary artery bypass grafting (CABG) and although usually benign can cause hemodynamic instability, prolong hospital stay and increase costs, and, rarely, predispose to a cerebrovascular accident. ${ }^{1}$

Pericardial effusions are incriminated in the development of SVT after CABG. ${ }^{2}$ Posterior pericardiotomy has recently been reported to reduce the incidence of echocardiographically defined pericardial effusions from $40 \%$ in a control group to $8 \%$ in a pericardiotomy group with 